\title{
Toxicopathological changes on Wistar rat after multiple exposures to acetamiprid
}

\author{
S. Mondal ${ }^{1}$, R. C. Ghosh ${ }^{2}$, S.S. Karnam² and Kamal Purohit ${ }^{3}$
}

1. Department of Veterinary Pathology, West Bengal University of Animal and Fishery Sciences, Kolkata, West Bengal, India; 2. Department of Veterinary Pathology, College of Veterinary Science and Animal Husbandry, Durg, Chhattisgarh, India; 3. Department of Veterinary Pathology, Rajasthan University of Veterinary \& Animal Sciences, Rajasthan, India.

Corresponding author: Shiv Shankar Karnam, e-mail: dr.shiv.vet82@gmail.com, SM: vetsamiran@gmail.com, RCG: rcghosh@rediffmail.com, KP: drkpurohit@rediffmail.com

Received: 19-08-2014, Revised: 31-10-2014, Accepted: 03-11-2014, Published online: 09-12-2014

doi: 10.14202/vetworld.2014.1058-1065. How to cite this article: Mondal S, Ghosh RC, Karnam SS, Purohit K (2014) Toxicopathological changes on Wistar rat after multiple exposures to acetamiprid, Veterinary World 7(12): 1058-1065.

\begin{abstract}
Aim: To see the toxicopathological changes after multiple exposure to acetamiprid (ACP) and also to obtain more information regarding the manner in which ACP acts at cellular level.

Materials and Methods: A subacute toxicity study of ACP was undertaken in 72 female Wistar rats in four groups (18 each). Three different concentrations of ACP $(25,100$ and $200 \mathrm{mg} / \mathrm{kg}$ of body weight $)$ were administered orally to rats. Untreated rats served as control. Different plasma enzyme and analytes were measured. Gross and histopathological observations were noted in this experiment.
\end{abstract}

Result: There was a significant increase in the plasma enzymes tested in this experiment. There was a significant decrease in plasma glucose, cholesterol and low-density lipid. Necrotic and degenerative changes were observed in vital organs.

Conclusion: It is observed that ACP has the toxic potential (on liver, kidney, heart, ovary and brain) at sub lethal doses.

Keywords: acetamiprid, histopathology, Wistar rat.

\section{Introduction}

Pesticides are the chemical formulation increasingly used in agriculture, animal husbandry and public health operation to kill the insects, weeds and fungus and to get rid of insect transmitted diseases. The frequent and continuous use of pesticide has resulted in their widespread distribution in the environment. These pesticides are toxic not only to insects and pests but at different levels to animals and human beings [1]. These agrochemicals, if not properly used, may pose serious hazards to human and animal health. Therefore, the present-day concern is with regard to their judicious and proper use, so that they can be applied safely with proper instructions and guidance to have minimum risk to human and animal health [2]. The neonicotinoids, the newest major class of insecticides, have outstanding potency and systemic action for crop protection against piercing-sucking pests [3] and they are highly effective for flea control on cats and dogs [4]. Several neonicotinoids are harmful to honeybees, either by direct contact or ingestion. This may lead to a reduction in pollination [5].

Acetamiprid (ACP), a member of the neonicotinoid insecticide family. It is used in floriculture widely, on leafy vegetables, cole crops, citrus, cotton, ornamentals, and fruiting vegetables. Studies

Copyright: The authors. This article is an open access article licensed under the terms of the Creative Commons Attributin License (http:// creative commons.org/licenses/by/2.0) which permits unrestricted use, distribution and reproduction in any medium, provided the work is properly cited. found ACP concentration in bee collected materials, i.e., pollen, bee bread, honey and beeswax [6]. Widespread use of ACP is causing pesticide entry into the food chain, which in turn causing toxicity to man and animal. Information regarding selectivity of insecticide for judicial use may be generated only through properly designed laboratory and field studies.

It seems that a little work on the toxicopathological effect of ACP in rats has been done. Thus, there is an urgent need to obtain more information regarding the manner in which ACP acts at cellular level. The present study has been planned on rat as a model animal to see the pathological changes as an indirect exposure in human, domestic, as well as wild animal and poultry through feed.

\section{Materials and Methods}

\section{Ethical approval}

Experimental protocol was approved by Institutional Animal Ethics Committee before starting the experiment (Ethical No. - 445/01/a/CPCSEA).

\section{Animals}

The present study was conducted on 6 weeks old healthy Wistar female rats. The rats were procured and housed in cages at Animal House, College of Veterinary Science and Animal Husbandry (Indira Gandhi Krishi Vishwavidyalaya), Anjora, Durg, Chhattisgarh, India. Animals were allowed to acclimatize for a period of 7 days prior to experiment and provided standard feed (Nutri Lab, rodent feed, Vetcare Pvt. Ltd, Bangalore) and allowed purified water ad libitum. 


\section{Chemical}

ACP (extra pure, CAS No-135410-20-7) was procured from the Department of Veterinary Pharmacology and Toxicology, Indira Gandhi Krishi Vishwavidyalaya, Raipur, India. ACP was formulated using normal saline as a vehicle. ACP suspension was administered directly in the stomach by oral gavages with dose volume of $10 \mathrm{ml} / \mathrm{kg}$. Body weights were recorded before administration of ACP. The daily oral administration was continued for 28 days.

\section{Experimental design}

A preliminary dose-range-finding study was done to determine the dose of ACP in female Wistar rats for subacute toxicity study. For subacute toxicity study, 72 female Wistar rats were randomly selected and divided into four groups (Groups I, II, III and IV) each containing 18 rats. Highest dose was given ( $200 \mathrm{mg} / \mathrm{kg}$ body weight) to Group IV based on the preliminary dose range - finding study showing tremors, excessive salivation and hyper aesthesia, whereas the low dose that is, $25 \mathrm{mg} / \mathrm{kg}$ body weight showing only very mild salivation compared to control group was administered to Group II daily for 28 days. Medium dose of $100 \mathrm{mg} / \mathrm{kg}$ body weight was selected as Group III, showing watery salivation and tremors in the pilot study (Group III was administered $100 \mathrm{mg} / \mathrm{kg}$ body weight). At the end of the experiment on day 28 plasma samples were collected before final culling of rats for the estimation of some biochemical parameters. Blood was collected by retro-orbital bleeding. Heparin (sodium salt) was used as an anticoagulant (10 IU $/ \mathrm{ml}$; Gland Pharma Limited, India). Rats were kept in desiccators and anaesthetized using absorbent cotton soaked in isoflurane (Baxter, UK) during blood collection.

\section{Histopathology}

All the rats sacrificed (using guillotines under anesthesia) on day 28 were examined by conducting postmortem examination for the presence of gross pathological changes and then tissue samples were collected in 10\% neutral buffered formalin for histopathological examination. For histopathological examination, a routine procedure adopted at Department of Veterinary Pathology, College of Veterinary Science and Animal Husbandry, Durg, India, were employed. Tissue sections were cut between 3 and $5 \mu$ and stained with hematoxylin and eosin stain.

\section{Plasma analytes}

Alanine aminotransferase (ALT), aspartate aminotransferase (AST) and alkaline phosphatase (ALP) level in the blood was measured by using kit (Bayer Diagnostics India Ltd.) on ERBA Chem-5 autoanalyzer (Transasia, Italy) as described in literature provided by manufacturer. Enzyme level was expressed as $\mathrm{u} / \mathrm{l}$. Acid phosphatase level in was measured by using Kit (Teco Diagnostics, Anahei, CA 92807 U.S.A.) from Core System on Photometer ERBA Chem-5 autoanalyzer (Transasia, Italy) as described in the literature provided by manufacturer. Acid phosphatase was expressed as IU/L.

Glucose, Triglyceride, cholesterol and high-density lipoprotein (HDL) levels in blood were estimated by standard kit (Bayer Diagnostics India Ltd.) in spectrophotometer (AE-11M, ERMA Inc., Tokyo, Japan) with the method as described in literature provided by manufacturer.

Low-density lipid level in the plasma was measured by using Friedewald's equation:

Low density lipoprotein (LDL)-cholesterol $=$ Total cholesterol - (Triglycerides)/5 - HDL

Very LDL (VLDL) level in the plasma was measured using the formula:

VLDL $=($ Triglycerides $) / 5$

The unit for the measurement of lipid profile was expressed as $\mathrm{mg} / \mathrm{dl}$.

\section{Statistical analysis}

Statistical analysis was carried out by using oneway ANOVA followed by Dunnett's multiple comparison test in Graph Pad Prism version-5 (GraphPad Software, Inc. USA).

\section{Photography}

Photography was carried out by using cyber shot DSC-P200 (Sony Corp., Japan).

\section{Results}

The effect of the ACP on plasma enzymes and analytes in female Wistar rats during sub-acute toxicity study is given in Table-1. There was a significant increase in the level of plasma AST of rats of both $100 \mathrm{mg} / \mathrm{kg}$ Group and IV compared to rats of the control group. However, in $25 \mathrm{mg} / \mathrm{kg}$ group the increase in the level of plasma AST was found to be non-significant $(p \leq 0.05)$ compared to rats of the control group. There was dose dependent significant $(p \leq 0.05)$ increase in plasma level of ALT and ALP activity in the ACP treated rats compared to rats of the control group. There was significant $(p \leq 0.05)$ increase in the activity of acid phosphatase of rats of Group IV compared to rats of the control group. There was significant $(\mathrm{p} \leq 0.05)$ decrease in the plasma glucose level of rats of 100 and $200 \mathrm{mg} / \mathrm{kg}$ group compared to rats of the control group. The mean values of plasma level of triglyceride, cholesterol, HDL, LDL and VLDL for each experimental group are presented in Table-1. Non-significant increase in the mean values of triglyceride, HDL and VLDL, were found in rats of Group II, III and IV compared to rats of the control group. An effect of daily oral administration of ACP for 28 days on plasma level of cholesterol and LDL was dose-dependent $(\mathrm{p} \leq 0.05)$.

\section{Gross pathology}

Liver: In the control group, no gross lesions were noticed in liver at necropsy. Petechial hemorrhages were observed in liver of rats of $100 \mathrm{mg} / \mathrm{kg}$ group. Liver of rats of $200 \mathrm{mg} / \mathrm{kg}$ group showed a 
Table-1: Effect of acetamipirid on plasma level of different analytes after sub-acute exposure.

\begin{tabular}{|c|c|c|c|c|}
\hline Parameters & Group I (control) & Group II (25 mg/ kg) & Group III $(100 \mathrm{mg} / \mathrm{kg})$ & Group IV (200 mg/kg) \\
\hline Triglyceride (mg/dl) & $39.02 \pm 6.60$ & $40.88 \pm 0.83$ & $45.39 \pm 1.75$ & $47.41 \pm 1.36$ \\
\hline Cholesterol (mg/dl) & $43.75 \pm 0.68$ & $36.48 \pm 1.39$ & $35.28 \pm 2.60 *$ & $30.94 \pm 0.76 * *$ \\
\hline $\mathrm{HDL}(\mathrm{mg} / \mathrm{dl})$ & $9.75 \pm 0.69$ & $10.05 \pm 1.94$ & $11.42 \pm 0.82$ & $12.78 \pm 2.33$ \\
\hline LDL (mg/dl) & $24.53 \pm 1.41$ & $17.65 \pm 1.66 *$ & $14.32 \pm 1.37 * *$ & $11.40 \pm 1.82 * *$ \\
\hline $\operatorname{VLDL}(\mathrm{mg} / \mathrm{dl})$ & $7.80 \pm 1.32$ & $8.18 \pm 0.17$ & $9.08 \pm 0.35$ & $9.48 \pm 0.27$ \\
\hline Glucose (mg/dl) & $85.50 \pm 1.06$ & $85.33 \pm 4.05$ & $67.00 \pm 3.68^{*}$ & $48.67 \pm 0.41 * *$ \\
\hline AST $(U / L)$ & $44.17 \pm 2.26$ & $52.00 \pm 2.42$ & $130.05 \pm 1.84 * *$ & $158.92 \pm 5.25^{* *}$ \\
\hline ALT (U/L) & $37.31 \pm 1.33$ & $57.24 \pm 3.123 * *$ & $77.78 \pm 2.843 * *$ & $115.25 \pm 2.74 * *$ \\
\hline $\operatorname{ALP}(U / L)$ & $36.00 \pm 2.45$ & $57.27 \pm 9.70 * *$ & $85.03 \pm 15.81 * *$ & $105.77 \pm 6.08 * *$ \\
\hline Acid phosphatase (IU/L) & $5.13 \pm 0.62$ & $8.21 \pm 1.58$ & $12.11 \pm 0.33$ & $20.36 \pm 6.09 * *$ \\
\hline
\end{tabular}

$* p \leq 0.05, * * p \leq 0.01$ as compared with control (Group I), ALP=Alkaline phosphatase, ALT=Alanine aminotransferase, AST $=$ Aspartate aminotransferase

slight enlargement and petechial hemorrhages. Livers of rats of $200 \mathrm{mg} / \mathrm{kg}$ group were also found to be of pale yellow in color, friable and with rounded edges indicating fatty changes (Figure-1a).

Lungs: Focal hemorrhages were noticed in lungs of rats of $25 \mathrm{mg} / \mathrm{kg}$ group. Some rats of $25 \mathrm{mg} / \mathrm{kg}$ group showed pneumonia. Ecchymotic hemorrhages (Figure-2a) and severe consolidation of lung were observed during post mortem examination of the rats of $100 \mathrm{mg} / \mathrm{kg}$ group. Rats of $100 \mathrm{mg} / \mathrm{kg}$ group also showed severe hemorrhagic pneumonia. The lungs of rats of $200 \mathrm{mg} / \mathrm{kg}$ group showed the atelectasis.

Kidney: Grossly there were no changes found in the kidneys of rats of Group I and II. enlargement of the kidneys were found in the rats of both groups $100 \mathrm{mg} / \mathrm{kg}$ group and $200 \mathrm{mg} / \mathrm{kg}$ group (Figure-3a).

Spleen: There were no changes recorded at necropsy in spleen of rats in all experimental groups except a slight decrease in size of spleen in the rats of $200 \mathrm{mg} / \mathrm{kg}$ group.

Heart: Hearts of rats of all the experimental groups found to be normal at necropsy.

Ovary: Congestion was observed in the ovary of rats of $200 \mathrm{mg} / \mathrm{kg}$ group. No gross changes were found in any other groups.

Brain: No gross lesions were observed in the brain of rats of any of the groups of experiment.

\section{Histopathology}

Liver: Severity of changes in the liver was dose dependent. Mild degenerative changes were seen in liver of rats of $25 \mathrm{mg} / \mathrm{kg}$ group. Mild fatty changes and increase eosinophilia were also observed under microscope in liver of rats of $25 \mathrm{mg} / \mathrm{kg}$ group (Figure-1b). In the rats of $100 \mathrm{mg} / \mathrm{kg}$ group, the liver showed increased granularity of the cytoplasm. There were severe fatty changes and necrosis in the liver of rats of $100 \mathrm{mg} / \mathrm{kg}$ group (Figure-1c). Liver of rats of $200 \mathrm{mg} / \mathrm{kg}$ group showed severe fatty changes in the hepatocytes towards the periphery of the liver. Increase eosinophilia was also observed indicating degenerative changes. There were focal necroses leading to lysis of hepatocytes (Figure-1d).

Lungs: The effects of ACP in lungs of female Wistar rats were dose dependent. Lungs of rats of

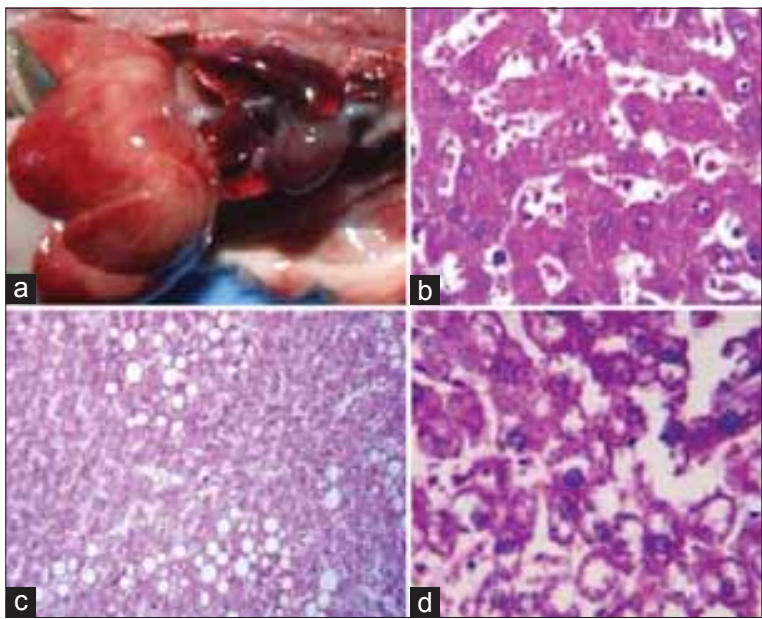

Figure-1: (a) Livers of rats of $200 \mathrm{mg} / \mathrm{kg}$ group showing pale color, friable and with round edges, (b) Mild fatty changes and increase eosinophilia in liver of rats of $25 \mathrm{mg} / \mathrm{kg}$ group, (c) The liver $100 \mathrm{mg} / \mathrm{kg}$ group showed increase granularity of the cytoplasm, severe fatty changes and necrosis, (d) Fatty changes, eosinophilia, focal necrosis leading to lysis of hepatocytes in $200 \mathrm{mg} / \mathrm{kg}$ group.

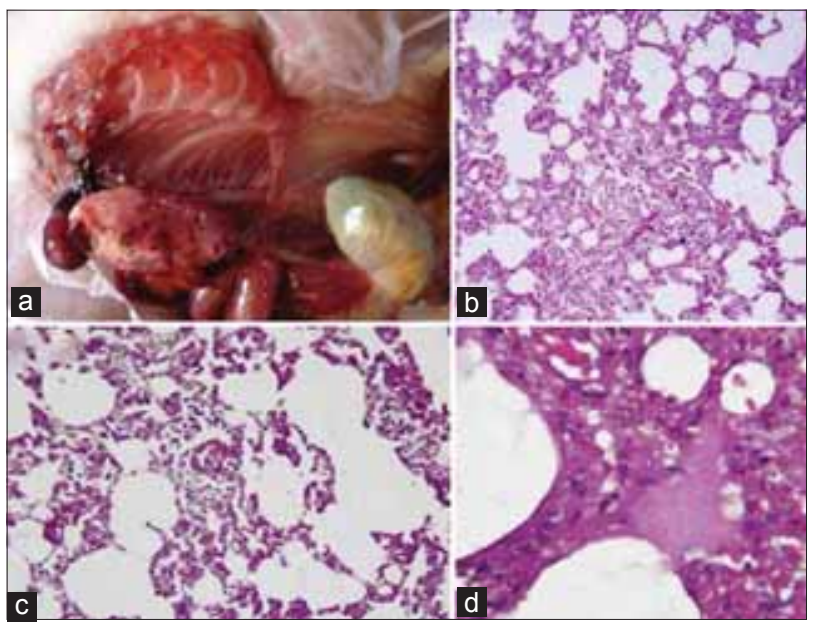

Figure-2: (a) Echymotic hemorrhages in $25 \mathrm{mg} / \mathrm{kg}$ group, (b) Mild congestion and thickening of alveolar septa in $25 \mathrm{mg} / \mathrm{kg}$ group, (c) In $100 \mathrm{mg} / \mathrm{kg}$ group bronchi of rats filled with mononuclear cells and red blood cells, emphysema and thickening of alveolar septa, (d) Severe hemorrhages and edema in lungs of rats of $200 \mathrm{mg} / \mathrm{kg}$ group.

$25 \mathrm{mg} / \mathrm{kg}$ group showed interstitial pneumonia. There were also hypertrophy of alveoli, mild congestion and 


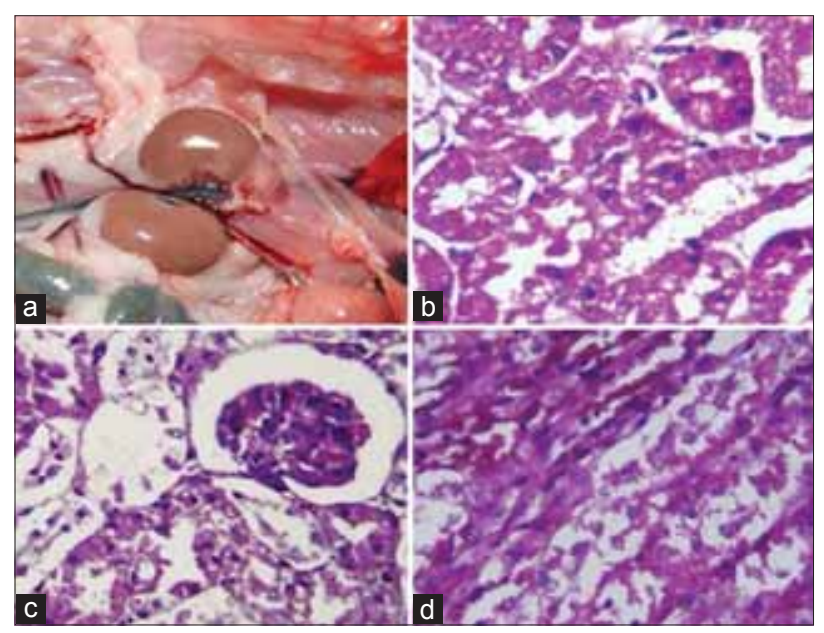

Figure-3: (a) Enlargement of the kidneys in $200 \mathrm{mg} / \mathrm{kg}$ group, (b) Moderate degree of degeneration and necrotic changes in proximal and distal convoluted tubule in the rats of $25 \mathrm{mg} / \mathrm{kg}$ group, (c) In rats of $100 \mathrm{mg} / \mathrm{kg}$ group showed congestion, hemorrhages and necrosed tubules, (d) Rats of $200 \mathrm{mg} / \mathrm{kg}$ group revealed complete lyses leaving reticular framework.

thickening of alveolar septa (Figure-2b). In $100 \mathrm{mg} / \mathrm{kg}$ group bronchi of some rats were filled with mononuclear cells and red blood cells (RBCs). There were also emphysema and thickening of alveolar septa (Figure-2c). Moderate degree of edema was also noted in lung of rats of $100 \mathrm{mg} / \mathrm{kg}$ group. There were severe hemorrhage and edema in lungs of rats of $200 \mathrm{mg} / \mathrm{kg}$ group (Figure-2d). There was also thickening of alveolar septae.

Kidney: Moderate degree of degenerative and necrotic changes in proximal convoluted tubules (PCT) and distal convoluted tubules (DCT) was found to be noted in the rats of $25 \mathrm{mg} / \mathrm{kg}$ group (Figure-3b). In the rats of $100 \mathrm{mg} / \mathrm{kg}$ group there were congestion and hemorrhages in kidney. Moderate degenerative and necrotic changes were noted in the rats of $100 \mathrm{mg} / \mathrm{kg}$ group (Figure-3c). Rats of $200 \mathrm{mg} / \mathrm{kg}$ group revealed degenerative and necrotic changes in PCT and DCT of kidney. In some area of kidney tubular cells had undergone complete lyses leaving reticular framework (Figure-3d).

Spleen: Depletion of lymphocytes in the periarteriolar lymphoid sheath and marginal zone in white pulp was observed in spleen from rats of $25 \mathrm{mg} / \mathrm{kg}$ group (Figure-4a). Spleen of rats of $100 \mathrm{mg} / \mathrm{kg}$ group showed severe depletion of lymphocyte from malpighian corpuscle and hemorrhages (Figures- $4 b$ and c). In spleen of rats of $200 \mathrm{mg} / \mathrm{kg}$ group there was also severe depletion of lymphocytes from the malphigian corpuscle (Figure-4d).

Heart: There was hemorrhage in myocardium in rats of $200 \mathrm{mg} / \mathrm{kg}$ group. Overall alterations in heart due to ACP toxicity in high dose group was degenerative and necrotic change in cardiac muscle cells. Some areas of the heart in rats of $200 \mathrm{mg} / \mathrm{kg}$ group were hyalinized (Figure-5a). Necrosis was found in the heart of rats of $100 \mathrm{mg} / \mathrm{kg}$ group. In this group, the

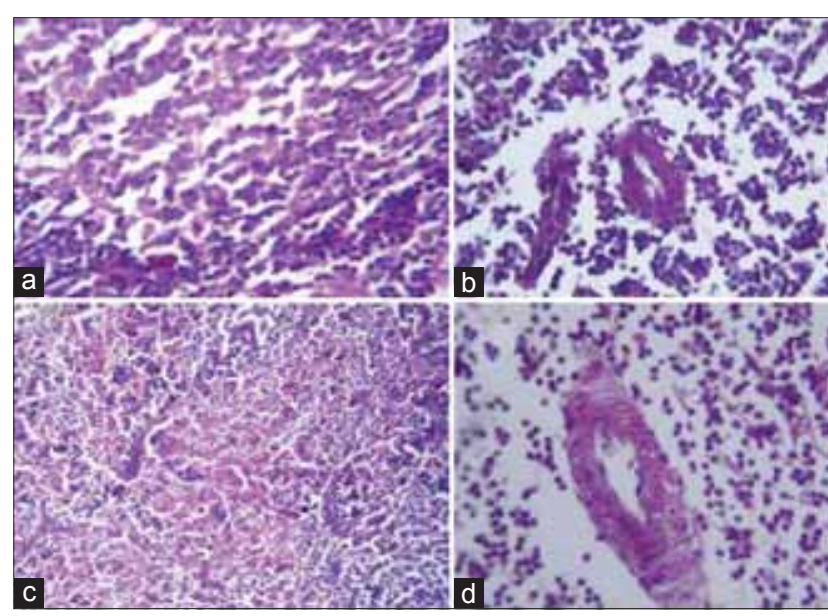

Figure-4: (a) Depletion of lymphocytes in the periarteriolar lymphoid sheath and marginal zone in white pulp in spleen from rats of $25 \mathrm{mg} / \mathrm{kg}$ group, (b and c) Spleen of rats $100 \mathrm{mg} / \mathrm{kg}$ group showed severe depletion of lymphocytes from malpighian corpuscles and hemorrhages, (d) In spleen of rats of $200 \mathrm{mg} / \mathrm{kg}$ group showing severe depletion of lymphocytes from the malphigian corpuscle.

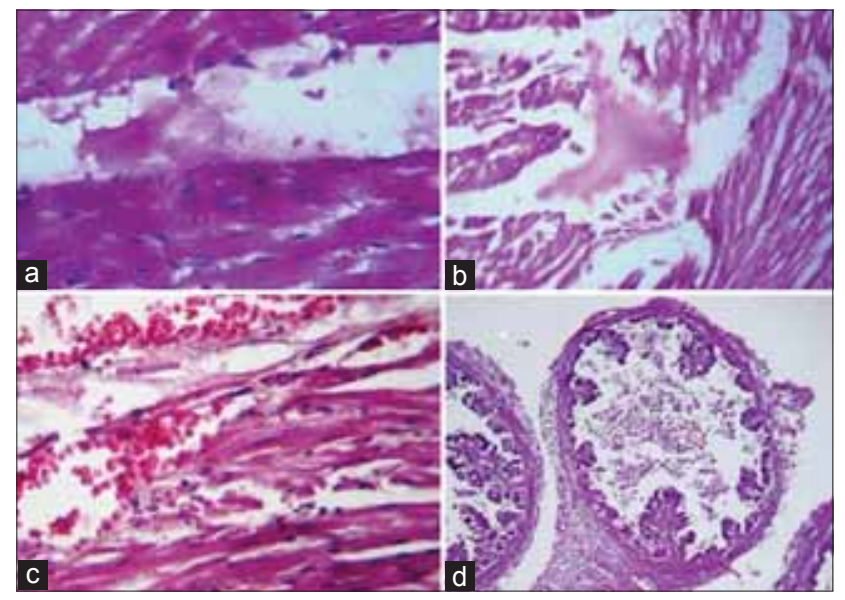

Figure-5: (a) Some areas of heart in rats of $200 \mathrm{mg} / \mathrm{kg}$ group were hyalinized, (b) In heart of rats of $100 \mathrm{mg} / \mathrm{kg}$ group showed edema, (c) In rats of $25 \mathrm{mg} / \mathrm{kg}$ group, mild hemorrhages in epicardium and edema, (d) Severe degeneration changes in fallopian tube of $200 \mathrm{mg} / \mathrm{kg}$ dose group, where the mucosal fold were significantly regressed and filled with mononuclear cells.

heart showed edema (Figure-5b). In some of the rats of $25 \mathrm{mg} / \mathrm{kg}$ group, mild hemorrhages in epicardium and edema (Figure-5c) were observed during microscopic examination.

Ovary: Ovary showed a mild necrotic change in the medullar parenchyma in high dose group. Severe degenerative changes were observed in fallopian tube where the mucosal fold were significantly regressed and filled with mononuclear cells (Figure-5d).

Brain: Neural degeneration was found in brains of rats of $200 \mathrm{mg} / \mathrm{kg}$ group (Figure-6a). Mild degenerative changes and hemorrhages were observed in brain of rats of $100 \mathrm{mg} / \mathrm{kg}$ group (Figure-6b). However, no significant histological alteration could be seen in the section of the brain of rats of Group II. 


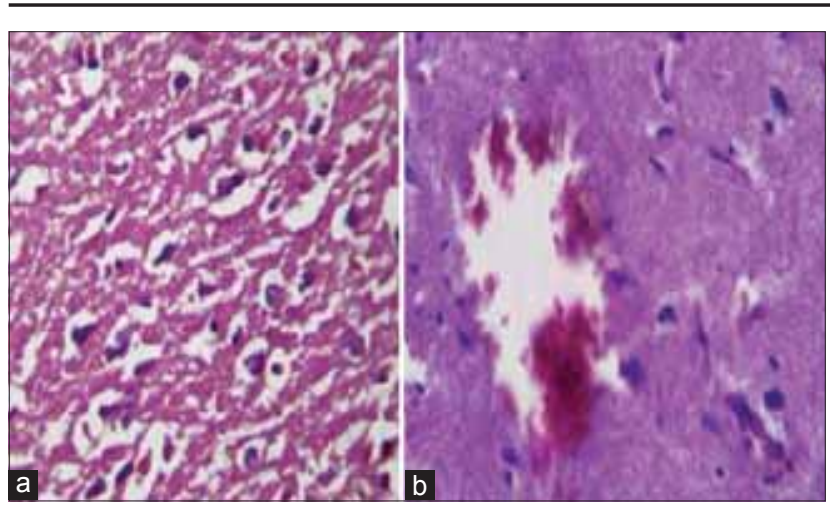

Figure-6: (a) Neural degeneration in brains of rats of $200 \mathrm{mg} / \mathrm{kg}$ group, (b) Mild degenerative changes and hemorrhages in the brain of rats of $100 \mathrm{mg} / \mathrm{kg}$ group.

\section{Discussion}

Significant increase in plasma AST activity in ACP treated rats suggests an increased respiratory burst and mitochondrial involvement as AST is chiefly a mitochondrial enzyme. Mitochondrion plays an important role in maintaining hepatocyte integrity and function, which may be hampered due to excessive physiologic stress [7]. Activity of AST is high in acute and chronic liver injury [8]. Elevation in the AST can be associated with cell necrosis of many tissues. Pathology involving the skeletal or cardiac muscle and/or the hepatic parenchyma allows the leakage of a large amount of this enzyme into the blood. The elevation in AST is produced by the ACP is an indication of widespread tissue damage.

ALT is a key cytoplasmic enzyme present in liver and other cells. It is particularly useful in measuring hepatic necrosis, especially in small animals [9]. ALT is employed as a marker of hepatocellular damage and in general ALT is considered a more sensitive indicator of liver cell injury than AST [10]. Though AST and ALT are not known to have any function in the plasma, but their increase level in the blood indicate cellular damage and increased membrane permeability [11] and their altered metabolism. Although it is difficult to point the damage to any particular organ by ACP, increased levels of aminotransferases in rats may be attributed to liver damage, as it is the primary organ of biotransformation of ACP. ALP, a brush border enzyme having of organic phosphatase esters mediates membrane transport at optimum $\mathrm{pH}$ between 9 and 10 [12]. They are zinc metalloenzymes that are composed of two identical subunits arranged around an active center. It is known to be involved in a variety of activities such as permeability, growth and cell differentiation. The elevation in plasma in ALP activities in female Wistar rats are not in accordance with the findings of Bhardwaj et al. [13] who reported augmented level of ALP activity in rats following 90 days of oral administration of imidacloprid. Release of ALP usually occurs due to its increased synthesis brought about by variety of liver conditions. Elevated plasma ALP might be due to destruction of epithelial cells in gastro intestinal tracts [13]. Significant increased levels of ALP in ACP treated rats suggest alteration in membrane structure as ALP is a plasma membrane enzyme. The level of a significant increase of acid phosphatase is in accordance with the findings of Mishra and Kuswah [14]. Acid phosphatases belong to a class of enzymes called hydrolases, and they are characterized by their ability to hydrolyze a large variety of organic phosphate esters with the formation of an alcohol and a phosphate ion [12]. Significantly increased plasma levels of acid phosphatase in the ACP treated rats indicate increased lysosomal activity in liver of rats, leading to the leakage of excessive enzyme into the plasma.

In the present study, hypoglycemia was observed on $28^{\text {th }}$ day and there was a dose-dependent decrease in glucose concentration after 28 days of oral administration of ACP. The results of the present study showed that dose-related decrease in the level of blood glucose is in agreement with the observation of Jain and Punia [15] in imidacloprid treated rats. Studies on rats have indicated that thyroid could be sensitive to ACP. As ACP and imidacloprid both are nitroguanidine insecticide and have structural similarity, ACP can also affect thyroid function. Hypoglycemia also occurred on feeding of broiler chicks with fenvalerate $(20 \mathrm{ppm})$, monocrotophos (2 ppm) and endosulfan (2 ppm) for 8 weeks [16].

Significant $(p \leq 0.05)$ decrease of cholesterol in rats of both 100 and $200 \mathrm{mg} / \mathrm{kg}$ group may be due to hyperthyroidism. Hydroxymethylglutaryl (HMG$\mathrm{CoA}$ ) reductase is the primary control point for cholesterol synthesis [17]. Hepatic HMG-CoA reductase is inhibited by phosphorylation of the enzyme. The protein kinase system responsible for the phosphorylation of HMG-CoA reductase is stimulated by intracellular cyclic activated protein kinase (cAMP). Hepatic intracellular cAMP levels are controlled in part by plasma glucagons, which decrease it. Condition that increase glucagons (e.g. fasting) would decrease cholesterol synthesis [18]. In the present study, ACP could possibly affect in feed intake of the animal and cause animal to be off fed. Increase in the triglyceride levels indirectly indicating either decrease in circulating insulin level or decrease in insulin receptor and also liver damage in rats of both groups. Due to the cumulative effect of partial liver damage and drop in either insulin level or insulin receptor, there was a reduction in cholesterol level in rats of both the group than the rats of the control group. Report available on plasma cholesterol levels in ACP treated rats is scanty. However, Ayub Shah and Gupta [19] observed a marginal increase in serum cholesterol levels in rats due to low doses (@24-54 mg $/ \mathrm{kg}$ body weight) of permethrin but at higher doses (@ 80-120 mg/kg body weight) the levels of serum cholesterol of rats reduced significantly.

Report on pathology in ACP toxicity in rats is scanty in the available literature. However, Piramanayagam and Manohar [20] reported mottling 
of liver in gross changes induced by malathion toxicity in rats. Bhelonde [21] documented enlargement of liver in rats (@5.916 mg/kg body weight) in fenpropathrin toxicity. Tamuli et al. [22] reported mild to severe degree of emphysema covering the whole organ barring a few areas where they also observed congestion and moderate hemorrhages in calves in paraquat intoxication. They recorded no gross lesions in the kidneys of the calves, except perirenal gelatinization of fat during paraquat intoxication. An enlargement of sinusoids, degeneration of hepatic cords and hepatocytes and vacuole formation [23] in hepatocyte in rat liver were observed in intoxication. Kaushal et al. [24] reported congestion and mildzonal granular to vacular degenerative changes in liver on nitrosodiethylamine (NDEA) administration under conditions of low dietary protein level in albino rats. Anoxia can cause vacuolar degeneration of the parenchymatous tissues. In the present study, congestion and reduction in blood circulation might have caused anoxia, which resulted in vacuolar degeneration in the hepatocytes. From adipose tissue, lipids are released and transported as free fatty acids. Free fatty acids enter the liver cell and most are esterified to triglyceride in order to be secreted by liver, intercellular triglyceride must be complexed with specific apoprotein molecules called "lipid acceptor protein" to form lipoprotein [25]. ACP could possibly be a hepatotoxin that alters mitochondrial and microsomal functions. Increase free fatty acid synthesis, diminished triglyceride utilization, decrease fatty acid oxidation, a block in lipoprotein excretion and enhanced lipolysis increase delivery and uptake of free fatty acids leading to ACP induced fatty liver. Reports on histopathological studies on lungs of female rats in ACP toxicity are scanty in the available literature. However, microscopic lesions of the lungs in paraquat toxicity in calves revealed varying degree of emphysema, moderate congestion and hemorrhages around the pulmonary vessels and interstitial spaces [22]. They also indicated edema in lungs during histologic examination of calves. Severe congestion, moderate interstitial reactions and mild pleuritis in lungs were reported by Kaushal et al. [24] in NDEA induced oxidative stress in albino rats. Hemorrhages and thickened interalveolar septae with infiltration of mononuclear cells in lungs were reported after benzalkonium administration [26]. In the present study, the lung lesions may be the result of cyclic reduction oxidation of ACP, which were brought via circulation with subsequent release of superoxide radicals leading to lipid peroxidation in the cell of the alveolar wall. Congestion was seen in blood vessels. Bronchi and bronchioles were filled with exudates and RBC, and this extended into the interstitial spaces. Because of infiltration, the interalveolar septa were thickened. The poisonous substances cause damage in vascular endothelium as well as to the alveolar epithelial cells. As a result of damage in vascular endothelium and increased vascular permeability excessive fluid and plasma proteins leaks out initially into the interstitium and subsequently into the alveoli [27]. Degeneration of the epithelial cells of the renal PCT has been found in the toxicity of asbestos [28]. Severe congestion of the blood vessels, desquamation or coagulative necrosis of the epithelial cells of the tubules and proliferation of the endothelial cells of the glomeruli were seen in the kidney of goats due to cypermethrin intoxication [29]. Whereas, mild degenerative changes such as cellular swelling and necrosis were noticed in rats receiving cypermethrin [30] Coagulative necrosis and degeneration of tubular epithelium were reported by Kaushal et al. [24] in NDEA induced oxidative stress in albino rats. In the present experiment possibly progressive dehydration in $100 \mathrm{mg} / \mathrm{kg}$ group and IV causing decrease in glomerular filtration rate and lesser blood supply through efferent artery to PCT and DCT resulted in low nutrient supply leading necrosis and lysis of the cell.

Cha et al. [31] observed depletion of spleen lymphocytes in the periarteriolar lymphoid sheath and marginal zone in white pulp. The depletion of lymphocytes in the malpighian corpuscles and subsequent necrosis of white pulp have also been reported in toxicity studies [32] However, in histopathological findings of imidacloprid toxicity in rats Gatne et al. [33] reported depopulation of lymphocytes, mild fibrous tissue proliferation and thickening of capsule in spleen of all treated groups as compared to control group and the severity of the lesions was more at highest dose level (160 mg/kg body weight) that showed additional findings like disintegration of white pulp and focal necrosis. Congestion and decrease in number and size of lymphoid follicles in spleen were reported by Kaushal et al. [24] in NDEA induced oxidative stress in albino rats. The marked depletion of the lymphoid cells from the germinal center of the splenic follicles in the present study corroborates with the observation related to suppression of cell mediated immunity and indicated that ACP have immunosuppressive effects. Mondal et al. [2] also suggested that the immunosuppressive action of ACP is the reflection of the functional defect in immunocompetent cells, depletion of the responding cell type and alteration in normal hormone levels. Thus the suppression of cellular immune response as observed in the present study might be due to the result of the cytotoxic effect of ACP on T-lymphocyte.

Mild but focal areas of degeneration with mild congestion in myocardium have also been observed in rats due to doxoubicin toxicosis [34]. The lesions observed in the heart muscle might be due to the effect of disruption of oxidative phosphorylation. There are no reports in the available literature on female reproductive tract in ACP toxicity. Regression of mucosal fold and exudation in fallopian tube suggested that ACP E-modulate functional changes in female reproductive tract by interfering secretary and cilliary activities. The lesions observed in brain in the present study 
resembled the lesions reported by Piramanayagam and Monohar [20] in malathion toxicity in rats. They observed neuronal degeneration, gliosis, perivascular cuffing, neuronal necrosis and hemorrhages in the histological section of the brain tissues of malathion treated rats. In paraquat intoxication, Tamuli et al. [22] observed necrotic lesions in the cerebrum of the calves characterized by degenerated neurons, satellitosis and neuronophagia. They also observed focal distribution of congestion and hemorrhage in brain of paraquat-intoxicated calves. Moderate gliosis and astrocytic proliferation in the present study [35] could be a direct effect of the toxin (ACP) coupled with interference of ionotropic receptor as observed in a report [36].

\section{Conclusion}

It seems that the ACP at the dose levels tested in the present study for a period of 28 days may not have such extensive neurotoxic effects but at chronic exposure this insecticide can alter the functional attribute of brain. The above findings suggested that the liver being the major detoxifying organ suffered the maximum damage while kidneys as the excretory organ also shared the damage. It is now clear that more studies are required to understand the toxicity of ACP on animal health hazards and establish guidelines for acceptable residues in the environment.

\section{Authors' Contributions}

RCG and SM designed the experiment, sample collection and Experiment was performed by SM and SSK under supervision of RCG. Manuscript preparation was supervised, reviewed and edited by RCG and KP. All authors read and approved the final manuscript.

\section{Acknowledgments}

Financial support and infrastructural facilities provided by the Dean, College of veterinary science and animal husbandry, Anjora, Durg, Chhatisgarh, India, are acknowledged.

\section{Competing Interests}

The authors declare that they have no competing interests.

\section{References}

1. Mondal, S., Ghosh, R.C. and Mukhopadhyaya, S.K. (2012) Studies on the electrolytes and microelements in Wistar rat following multiple exposures to acetamiprid. Toxicol. Ind. Health, 28(5): 422-427.

2. Mondal, S., Ghosh, R.C., Mate, M.S. and Karmakar, D.B. (2009) Effects of acetamiprid on immune system in female wistar rats. Proc. Zool. Soc., 62(2): 109-117.

3. Mondal, S., Ghosh, R.C., Mate, M.S. and Karmakar, D.B. (2009) Effect of subacute exposure of acetamiprid on organ toxicity and growth of wistar rat. Indian J. Anim. Health, 48(2): 67-72.

4. Tomizawa, M. and Casida, J.E. (2005) Neonicotinoid insecticide toxicology: mechanisms of selective action. Annu. Rev. Pharmacol. Toxicol., 45: 247-268.
5. Blacquiere, T. and Smugghe, G. (2012) Neonicotinoids in bees: A review on concentrations, side-effects and risk assessment. Ecotoxicology, 21(4): 973-992.

6. Genersch, E., Von der Ohe, W., Kaatz, H., Schroeder, A., Otten, C., Buchler, R., Berg., S., Ritter, W., Muhlen, W., Gisder, S., Meixner, M., Leibig, G. and Rosenkranz, P. (2010) The Geman bee monitoring project: A long term study to understand periodically high winter lossess of honey bee colonies. Apidologie, 41: 332-352.

7. Hassanein, T. (2004) Mitochondrial dysfunction in liver disease and organ transplantation. Mitochondrion, 4: 609-620.

8. Tennant, B.C. (1997) Hepatic function. In: Kaneko, J.J., Harvey, J.W., Bruss, M.L., editors. Clinical Biochemistry in Domestic Animal. $5^{\text {th }}$ ed. Academic Press, San Diego. p327-352.

9. Cornelius, C.E. (1989) Liver function. In: Kaneko, J.J., editor. Clinical Biochemistry of Domestic Animals. Academic Press Inc., San Diego. p364-397.

10. Oser, B.L. (1976) Hawk"s Physiological Chemistry. McGraw-Hill Book Company, New York, London.

11. Sabina, E.P., Rasool, M., Vedi, M., Navaneethan, D., Ravichander, M., Parthasarthy, P. and Thella, S.R. (2013) Hepatoprotective and antioxidant potential of withania somnifera against paracetamol - induced liver damage in rats. Int. J. Pharm. Pharm. Sci., 5(2): 648-651.

12. Rombola, T.H., Pedrinho, E.A.N., Lemos, E.G., Gonçalves, A.M., Santos, L.F. and Pizauro, Jr, J.M. (2014) Identification and enzymatic characterization of acid phosphatase from Burkholderia gladioli. BMC Res. Notes, 7: 221.

13. Bhardwaj, S., Srivastava, M.K., Kapoor, U. and Srivastava, L.P. (2010) A 90 day oal toxicity of imidacloprid in female rats: morphological, biochemical and histopathological evaluations. Food Chem. Toxicol., 48(5):1185-1190.

14. Mishra, M. and Kuswah, H.S. (2007) Biochemical alternations in albino rats exposed to monocrotophos. Indian Vet. J. 84: 814-817.

15. Jain, S.K. and Punia, J.S (2006) Hematological and biochemical changes in subacute imidacloprid toxicity. Indian J. Anim. Sci., 76(3): 233-235.

16. Garg, U.K., Pal, A.K., Jha, G.J. and Jadhao, S.B. (2004) Haemato-biochemical and immunopathophysiological effects of chronic toxicity with synthetic pyrethroid, organophosphate and chlorinated pesticides in broiler chicks. Int. Immunopharmacol., 4: 1709-1722.

17. Sigler, R.E., Dominick, M.A. and Mcguire, E.J. (1992) Subacute toxicity of a halogenated pyrrole hydroxymethylglutaryl-coenzyme a reductase inhibitor in wistar rat. Toxicol. Pathol., 20: 595-602.

18. Yang, J., MacDougall, M.L. and McDowell, M.T. (2011) Polyomic profiling reveals significant hepatic metabolic alterations in glucagon- receptor (GCGR) knockout mice: Implications on anti-glucagon therapies for diabetes. $B M C$ Genomics, 12: 281-295.

19. Ayub Shah, M.A. and Gupta, P.K. (1997) Biochemicotoxicological study on permethrin- A synthetic pyrethroid insecticide in rats. Indian J. Toxicol., 4(1): 57-60.

20. Piramanayagam, S. and Monohar, B.M. (2002) Histopathological changes induced by Malathion in rats. Indian Vet. J., 79: 114-117.

21. Bhelonde, J.J. (2001) Toxicopathological studies on danitol (fenpropathrin $10 \% \mathrm{EC}$ ) in rats. M.V.Sc Thesis Submitted to Indira Gandhi Krishi Vishwaviyalaya, Raipur, Chhattisgarh.

22. Tamuli, S.M., Baruah, G.K. and Ahmed, N. (2005) Pathology of paraquat toxicity in calves. Indian Vet. J., 82: 251-253.

23. Aravinthan, A., Verma, S., Coleman, N., Davies, S., Allison, M. and Alexander, G. (2012) Vacuolation in hepatocyte nuclei is a marker of senescence. J. Clin. Pathol., 65(6): 557-60.

24. Kaushal, V., Sharma, S., Brar, A.P.S. and Soni, G. (2007) NDEA induced oxidative stress in albino rats-impact of dietary protein level. Toxicol. Int., 14(1): 33-39. 
25. Kumar, V., Abbas, A.K. and Fausto, N. (2006) Cellular adaptation, cell injury and cell death. In: Robin and Cotran's Pathologic Basis of Disease. 7th ed. Reed Elsevier India Pvt. Ltd., New Delhi. p35-36.

26. Swiercz, R., Hałatek, T., Stetkiewicz, J., Wąsowicz, W., Kur, B., Grzelińska, Z. and Majcherek, W. (2013) Toxic effect in the lungs of rats after inhalation exposure to benzalkonium chloride. Int. J. Occup. Med. Environ. Health, 26(4): 647-656.

27. Rivolta, I., Lucchini, V., Rocchetti, M., Kolar, F. Palazzo, F., Zaza, A. and Miserocchi, G. (2011) Interstitial pressure and lung oedema in chronic hypoxia. Eur. Respir. J., 37(4): 943-949.

28. Nagai, H., Okazaki, Y., Chew, S.H., Misawa, N., Yasui, H. and Toyokuni, S. (2013) Deferasirox induces mesenchymal - Epithelial transition in crocidolite-induced mesothelial carcinogenesis in rats. Cancer Prev. Res., 6(11): 1222-1230.

29. Tripathi, S. and Srivastav A.K. (2010) Nephrotoxicity induced by long-term oral administration of different doses of chlorpyrifos. Toxicol. Ind. Health, 26(7): 439-447.

30. Abdallah, F.B., Fetoui, H., Zribi, N., Fakhfakh, F. and Keskes, L. (2012) Protective role of caffeic acid on lambda cyhalothrin-induced changes in sperm characteristics and testicular oxidative damage in rats. Toxicol. Ind. Health,
28(7): 639-647.

31. Cha, S.W., Gu, H.K., Lee, K.P., Lee, M.H., Han, S.S. and Jeong, T.C. (2000) Immunotxicity of ethyl carbamate in female BALB/c mice: role of esterase and cytochrome P-450. Toxicol. Lett., 115(3): 173-181.

32. Everds, N.E., Snyder, P.W., Bailey, K.L., Dianne, B.B., Creasy, D.M., Foley, G.L, Thomas, J.R. and Teresa, S. (2013) Interpreting stress responses during routine toxicity studies: A review of the biology, impact, and assessment. Toxicol. Pathol., 41(4): 560-614.

33. Gatne, M.M., Ramesh, B.P.S. and Deore, M.D. (2006) Immunotoxicity studies of imidacloprid in rats. Toxicol. Int., 13(2): 89-92.

34. Imbaby, S., Ewais, M., Essawy, S. and Farag, N. (2014) Cardioprotective effects of curcumin and nebivolol against doxorubicin-induced cardiac toxicity in rats. Hum. Exp. Toxicol., 33(8): 800-813.

35. Dennis, W.D. (2012) Parkinson's disease and parkinsonism, neuropathology, cold spring harb. Perspect. Med., 2(8): a009258.

36. Kahn, R., Karbat, I., Ilan, N., Cohen, L., Sokolov, S., Catterall, W.A., Gordon, D. and Gurevitz, M. (2009) Protein structure and folding: molecular requirements for recognition of brain voltage-gated sodium channels by scorpion \{alpha\}-toxins. J. Biol. Chem., 284(31): 20684-20691. 